\title{
MUJERES EMPRESARIAS EN EL SECTOR TURÍSTICO HUATULCO, OAXACA: LA MIRADA MASCULINA
}

\author{
Martha Marivel Mendoza Ontiveros \\ Néstor Guillermo González Ortiz
}

Universidad Autónoma del Estado de México

\section{RESUMEN}

En el turismo es habitual observar que las mujeres encuentran oportunidades de acceder a trabajos remunerados, pero además ofrece oportunidades de emprender negocios, de esta forma se puede encontrar a mujeres como empresarias o dueñas de negocios. El hecho de que una mujer contribuya al ingreso de la familia, la convierte en proveedora y comparta este rol con la pareja, llegando incluso a ganar más que los hombres, lo anterior puede contribuir a generar fricciones o conflictos en las relaciones entre géneros por el rol tradicional atribuido en una sociedad patriarcal a los varones de ser los proveedores, protectores y autoridad. En este texto se presentan los resultados de una investigación en la que se entrevistó a hombres que viven en el Centro Integralmente Planeado Bahías de Huatulco, México para conocer sus percepciones sobre la labor empresarial de las mujeres y cómo influye ésta en sus roles de género a la luz del modelo hegemónico de masculinidad. Los resultados indican que dicho modelo tiene fisuras, ya que a cambio de ser "ayudados" en su rol de proveedor, deben aceptar la participación de las mujeres en las decisiones de la familia y aprender a aceptar cierto nivel de independencia.

Palabras Claves: turismo, mujeres empresarias, percepciones, masculinidades 


\title{
ENTREPRENEURIAL WOMEN IN TOURISM SECTOR IN MEXICO: AN ANALYSIS FROM A MALE POINT OF VIEW
}

\author{
Martha Marivel Mendoza Ontiveros \\ Néstor Guillermo González Ortiz \\ Universidad Autónoma del Estado de México
}

\begin{abstract}
Despite the fact that it is common for women to have paid jobs in tourism, it also offers opportunities for them to be engaged in business. In this way, women can be found to work as entrepreneurs or business owners. The fact that a woman contributes to family income makes her a provider and thus shares this role with her partner. In some cases women even earn more than men, which may trigger frictions or conflicts in gender relations because of the traditional role attributed in a patriarchal society to men as providers, protectors and authority. This article presents the results of an investigation in which men living in the Integrally Planned Center Bays of Huatulco, Mexico, were interviewed about their perceptions of the work of women as business owners and how it affects their gender roles within a hegemonic model of masculinity. The results indicate that this model has fissures, and that in exchange for being "helped" in his role as provider, men must accept the participation of women in family decisions and learn to accept some level of independence.
\end{abstract}

Keywords: tourism, entrepreneur women, perceptions, masculinities 


\section{INTRODUCCIÓN}

El turismo es un fenómeno o fenómenos que dejan ver su influencia en los ámbitos de la producción, del ocio y del consumo, en la organización del territorio, en los modos de vida, en la visión de la propia historia e identidad o en la relación con el patrimonio cultural (Nogués, 2009). Además de ser válvula de escape de las tensiones, la fatiga del trabajo y de un regulador de los tiempos y los espacios, el turismo incide en los valores, en las costumbres y en los comportamientos. Asimismo moldea un nuevo marco para las relaciones entre géneros.

Las transformaciones en la sociedad receptora incluyen los cambios más inmediatos en la calidad de vida y el ajuste de la actividad cotidiana en las comunidades de destino. Por su parte, los impactos culturales abarcan cambios a largo plazo en las normas sociales, la cultura material y los estándares de vida, los cuales irán emergiendo gradualmente en una relación comunitaria (Santana, 1997). No obstante en muchos casos hacer esta distinción en la realidad resulta complicada.

Cabe señalar que el contacto entre visitante y los residentes locales puede dar como resultado beneficios o perjuicios para la población receptora dependiendo de la diferencia que exista entre las culturas y el tipo de relación que se establezca (Cooper et al., 2007), además, el grado con el cual los impactos socioculturales influyen en las personas depende de una serie de factores tales como el número y tipo de turistas, la naturaleza del desarrollo turístico de la zona y su ciclo del desarrollo (Castaño, 2005); de este modo, hay un gran número de factores que pueden detonar los impactos socioculturales $\mathrm{y}$, por otra parte, factores similares podrían provocar resultados diferentes en lugares distintos.

No obstante, es importante mencionar que sería un exceso culpar al turismo de todos los problemas que van ligados también a los cambios sociales que afectan a los destinos en proceso de modernización. El turismo puede acelerar el proceso, pero no los crea necesariamente (Lickorish et al., 2000), o bien, no se ha podido demostrar fehacientemente, qué cambios son producto del turismo y cuáles son consecuencia de otros factores como los medios de comunicación, la globalización, etc.

Uno de los primeros estudios que reportaron modificaciones en la estructura familiar y las relaciones entre géneros fue el trabajo de Swain (1989) en una comunidad indígena situada en la Comarca de San Blas en Panamá. En este lugar el desarrollo 
turístico generó una oportunidad de empleo para hombres y mujeres por igual. Esta autora afirma que los roles de género han definido la relación de los kuna con el turismo: las mujeres producen una forma de arte textil tradicional cosida en paneles con diseños bordados complejos y múltiples capas que conservan una imagen comercialmente positiva de autenticidad étnica, denominadas molas. Por su parte, los varones kuna producen y mantienen el foco político que define los contactos del grupo con los intereses externos, entre los que se encuentra el turismo.

Otro ejemplo de cambio en la estructura familiar y de género lo presentó Wilson (1979) quien identificó un resentimiento de los hombres jóvenes seychellianos hacia los turistas, ya que éstos se hicieron pretendientes o novios de las camareras de los hoteles de esta isla y además ellas ganaban mucho más que ellos. Los jóvenes resentidos sufrían la sensación de que se les había rebajado. Así la existencia de un desequilibrio existente entre el empleo masculino y femenino lleva a Wilson suponer que iba a llegar esta sociedad a una situación familiar matriarcal, siendo la generación más joven de mujeres la que experimentaba un cambio en la forma de vida, al tener una existencia mucho menos restrictiva como consecuencia de la obtención de empleos remunerados en lugar de estar confinadas en casa y tener que salir acompañadas a la calle.

En el turismo, por ser una actividad de servicios, es común observar que las mujeres encuentran oportunidades de acceder a trabajos remunerados como empleadas de hoteles, agencias de viaje, restaurantes, tiendas, etc., pero además el turismo ofrece oportunidades de emprender negocios, de esta forma se puede encontrar a mujeres como empresarias o dueñas de pequeños comercios o negocios. El hecho de que una mujer trabaje y contribuya al ingreso de la familia, la convierte en proveedora única, en el caso de jefas de familia, o compartir este rol con la pareja, llegando incluso a ganar más que los hombres, lo anterior puede contribuir a generar fricciones o conflictos en las relaciones de las mujeres con los hombres de su familia por el rol tradicional impuesto a los varones de ser los proveedores.

Sin embargo, los estudios en contextos turísticos o aquellos que buscan analizar los cambios que dicho fenómeno ocasiona en los habitantes de los destinos turísticos, se han centrado en las mujeres; frente a esto es importante, desde la perspectiva de las masculinidades conocer la percepción de los hombres sobre los cambios que experimentan las mujeres en su vida, relacionados con su independencia económica y la toma de decisiones al interior de su familia a partir de su incorporación al trabajo productivo. 
Una mujer que se dedica a la actividad empresarial incide en actividades que tradicionalmente le eran vedadas, y como lo demuestra el estudio de Fernández y Martínez (2010) lleva a algunas al empoderamiento como en el caso concreto de la mujer empresaria del sector turístico en Bahías de Huatulco, Oaxaca México. Si las mujeres que laboran en el sector turístico se empoderan, qué pasa con su esposo, padres, hijos o hermanos. No es posible suponer que se producen cambios en un género y que el otro se mantenga igual, por ello surge las siguientes interrogantes: ¿qué piensan los hombres cercanos a estas mujeres de su actividad como empresarias? ¿Las apoyan o las obstaculizan en su actividad fuera del hogar? ¿Les ha afectado en sus relaciones interpersonales de pareja?

De esta forma el objetivo de esta investigación fue identificar la percepción de los familiares varones de las mujeres empresarias en el sector turístico de Bahías de Huatulco sobre su labor empresarial y cómo influye ésta en sus roles de género. Este trabajo abona en el conocimiento de los efectos del turismo, pues éste proporciona oportunidades de empleo para las mujeres al ser un sector de servicios, a su vez, encuentran posibilidades para emprender un negocio propio, lo que las impulsa a tomar decisiones y con ello a adquirir más confianza en sí mismas, este proceso puede entenderse como de 'empoderamiento'. En este trabajo se revisan las percepciones de los maridos, padres o hijos sobre este proceso al contrastarlo con el modelo hegemónico de masculinidad.

El escrito inicia con la exposición de los conceptos que se utilizaron para analizar la información y alcanzar el objetivo de investigación. A continuación se describe el contexto de estudio. Posteriormente se detalla el proceso metodológico usado para recabar los datos durante el trabajo de campo. Luego se exponen los resultados y se finaliza con las consideraciones finales.

\section{Relaciones de género}

De acuerdo con Hegg et. al. (2005), el género se interioriza a través de la socialización, entendida como un complejo y detallado proceso cultural de incorporación de formas de representarse, valorar y actuar en el mundo. Las relaciones de género pueden ser definidas como los modos en que las culturas asignan funciones y responsabilidades distintas a las mujeres y a los hombres. A su vez, estas relaciones determinan las diversas formas de alcanzar recursos como el poder (De Felipe y Casero, 2007). Cuando las relaciones de género son disímiles, lo que ocurre hoy en mayor o menor grado en todas 
las sociedades, se dice que hay desigualdades funcionales ligadas a los roles de género (Calatrava, 2002).

Alatorre y Luna (citado en Hegg et al., 2005) afirman que tanto hombres como mujeres asumen posiciones diferenciales, concordando éstas con los rasgos de género que se atribuyen a los hombres y mujeres respectivamente. Así, mientras el hombre acepta ser la autoridad y hace todo por conseguirla, la mujer negocia, pero a partir de una posición subordinada y, en algunos casos, simplemente acata lo que el hombre plantea.

Entonces si se toma como punto de partida la anatomía de mujeres y de hombres, con sus características reproductivas, cada cultura establece un conjunto de prácticas, ideas, discursos y representaciones sociales que atribuyen características específicas a mujeres y a hombres. Esta construcción simbólica, que en las ciencias sociales se denomina género, se refiere a la "fabricación de las ideas de lo que deben ser los hombres y las mujeres, de lo que se supone es "propio" de cada sexo" (Lamas, 1995; 2).

Por su parte, Ortner (citado en Moore, 2004) señala que la mujer como consecuencia de su simbolización con la naturaleza por su capacidad reproductora, tiene una asociación espontanea con lo "doméstico" en oposición a lo "público", es decir, la mujer se relaciona con las labores del hogar y con el cuidado de los hijos, y el hombre dada su condición de proveedor es asociado a lo "público" tomando a este modelo como una estructura de poder jerárquico con la mujer como subordinada.

Sin embargo, estas asignaciones de doméstico/mujer y público/hombre se están quedando atrás, ahora tanto hombres como mujeres tienen que salir al espacio público para proveer a la familia por medio de trabajos remunerados, debido principalmente a las recurrentes crisis económicas.

\section{Masculinidad}

De acuerdo con el género asignado a un individuo se articulan las relaciones sociales, de esta manera, somos etiquetados como hombres si nacemos con pene asumiendo las actividades socialmente definidas en un modelo hegemónico que se caracteriza por asociar al hombre con lo "absoluto, con la norma, siendo la mujer lo diferente, lo que se sale de la norma” (Royo, 2012; 2). 
Los varones encuentran rituales de confirmación de su masculinidad, a través de espacios en los cuales se crean relaciones homosociales, y que no dejan de crear ambigüedad en los propios participantes (López y Güida, 2000), sin embargo, la masculinidad, de acuerdo con Díaz (2007), va siempre unida a determinadas cualidades, sobre todo asociadas con la fuerza, la violencia, la agresividad, la potencia, la inteligencia racional y la idea de que es necesario estar probando y probándose continuamente que "es hombre" y que se ha logrado alcanzar el modelo definido de "ser hombre".

Olavarría (2001) sostiene que uno de los papeles fundamentales asignados a los hombres es el trabajo productivo, a él se le debe su capacidad de constituir una familia y hacerse responsable de ella. La capacidad de proveer, en gran medida sustenta el orden al interior de la familia. Por lo tanto, la familia se convierte en un lugar de pertenencia de los hombres en los que pueden mantener, en alguna medida, su autoridad, ejerciendo poder cuando lo estiman pertinente. Pero con las crisis económicas y con el feminismo se ha hecho visible la incapacidad de los varones como proveedores en una proporción importante de los hogares, así el que proveía, el varón, era el jefe del hogar, la autoridad, posición que estaba y aún está refrendada por dispositivos legales que le confieren supremacía sobre la mujer y los hijos/as, puede estar empezando a fisurarse.

\section{Modelo hegemónico de masculinidad. Crisis y fisuras}

De acuerdo con Tena y Jiménez (2006), la construcción del modelo hegemónico implica que los varones para ser valorados como tales, deben manifestar características de comportamiento como racionalidad, invulnerabilidad emocional, competitividad, fortaleza física y autosuficiencia. Además de estas características también señalan y hacen hincapié, tales autores, en tres manifestaciones importantes que debe cumplir el hombre: protector, proveedor económico y ser quien detenta y aplica la autoridad dentro de su familia.

Cabe señalar que en una sociedad en donde se respete la diversidad y el derecho a elegir una manera de vida, este modelo de masculinidad puede resultar incompatible con los individuos, ya que habría un rechazo a la imposición de un único modelo de masculinidad (Boscán, 2008). Es decir, el modelo hegemónico "tiene más posibilidad de desarrollo en regímenes autoritarios que en los democráticos, en situaciones de bonanza económica y tranquilidad social que en situaciones de crisis y conflictividad" (Gálvez, 2007; 4). 
La masculinidad hegemónica cambia la manera de percibir al mundo y nuestra realidad cotidiana va indicando que este modelo es un modelo imperfecto (Díaz, 2007), ya que diversas crisis económicas, así como la liberación femenina ha hecho que cada vez más mujeres se hayan incorporado al mercado de trabajo, sin que esto implique el abandono del trabajo reproductivo que les está asignado en la familia nuclear patriarcal, sin embargo, para muchas mujeres la obtención de un ingreso es una forma de lograr autonomía y establecer relaciones de mayor equidad con los varones, aunque estos procesos de incorporación al mercado de trabajo no han ido acompañados de retribuciones equivalentes a las que tienen los varones.

Por lo anterior son muchos los hombres que no cumplen con un perfil de una masculinidad hegemónica por razones físicas, políticas, económicas, étnicas, sexuales, estas características nos hacen ver que este modelo hegemónico tiene fisuras o fallas que hacen posible que muchos hombres encuentren diferentes maneras de ser hombres (Díaz, 2007), sin embargo, pueden pasar muchos años para que los varones sean desplazados de ese lugar hegemónico, ya que es necesario que se demuestre que no son capaces de ejercerlo. Así que para que la mujer comparta o asuma esa posición de autoridad debe demostrar tal capacidad especialmente con la generación de recursos para mantener o mejorar la calidad de vida del núcleo familiar y así mantenerse en una posición con capacidad de negociar con el varón (Olavarría, 2001).

Ramírez y García (2002) mencionan que la masculinidad hegemónica no es fija, ni es la misma en todas sociedades ni a través de los tiempos. Atendiendo a lo anterior Boscán menciona que "un gran número de varones buscan hoy dejar de ser machistas, pero que no desean hacerse 'femeninos'. Muchos de ellos reconocen que ya no pueden seguir siendo sexistas y homofóbicos, pero no quieren dejar de ser masculinos" (2008; 95).

Connell (citado en Ramírez y García, 2002) identifica dos categorías para explicar las relaciones entre las masculinidades; "complicidad y subordinación"

- La masculinidad cómplice se caracteriza por la aceptación y reproducción de la masculinidad hegemónica por aquellos hombres que tienen contacto con la misma pero no la encarnan. Estos hombres no cumplen plenamente, o en gran medida, con las expectativas de la masculinidad hegemónica, pero se identifican 
con la misma y le dan todo su apoyo.

- La masculinidad hegemónica a su vez subordina, margina y devalúa a aquellos hombres que no cumplen con las exigencias que ella impone.

Ramírez y García (2002), además de las categorías de Connell añaden dos masculinidades, la contestataria y la hipermasculinidad

- La masculinidad contestataria es la representación de las identidades masculinas que activamente retan, cuestionan y rechazan la masculinidad hegemónica. Sus identidades y sexualidades no están formadas por el poder y el control. Los hombres que encarnan esta masculinidad propulsan activamente el desarrollo de formas alternas de relaciones entre los géneros y al interior de su propio género.

- La hipermasculinidad se caracteriza por la exageración de lo que se considera como "lo masculino", tanto en el cuerpo como en el comportamiento con tendencia a la rudeza, la violencia, la falta de afectividad y la agresividad.

\section{Percepción}

"La percepción es algo bastante más complejo que un simple mecanismo de captación visual del mundo que nos rodea" (Nogué, 1992; 46); la percepción abordada desde la psicología se define "como el proceso cognitivo de la conciencia que consiste en el reconocimiento, interpretación y significación para la elaboración de juicios en torno a las sensaciones obtenidas del ambiente fisico y social, en el que intervienen otros procesos psíquicos entre los que se encuentran el aprendizaje, la memoria y la simbolización" (Vargas, 1994; 48).

La percepción comprende dos procesos que, de acuerdo con Bruner y Cols (citados en Moya, 1999), son los siguientes:

1. La codificación o selección del enorme caudal de datos que nos llegan del exterior, reduciendo su complejidad y facilitando su almacenamiento y recuperación en la memoria

2. Un intento de ir más allá de la información obtenida, con el fin de predecir acontecimientos futuros $y$, de ese modo, evitar o reducir la sorpresa.

Vargas señala "que la percepción es biocultural, ya que, por un lado, depende 
de los estímulos físicos y sensaciones involucradas y, por otro lado, de la selección y organización de dichos estímulos y sensaciones" (1994; 47).

Punter (citado en Nogué, 1992) argumenta que todo proceso de percepción se enmarca en juego tres fases estrechamente interrelacionadas, aunque claramente diferenciables:

1. La experiencia sensorial: se refiere al papel de nuestros sentidos en la captación del entorno.

2. La cognición: comprende todo el conjunto de procesos a través de los cuales estructuramos la información que reciben nuestros sensores.

3. La evaluación o preferencia: referida a nuestras actitudes y preferencias en relación con lo aprehendido y estructurado previamente.

"La percepción depende de la ordenación, clasificación y elaboración de sistemas de categorías con los que se comparan los estímulos que el sujeto recibe, pues conforman los referentes perceptuales a través de los cuales se identifican las nuevas experiencias sensoriales transformándolas en eventos reconocibles y comprensibles dentro de la concepción colectiva de la realidad" (Vargas, 1994; 47).

\section{Centro Integralmente Planeado (CIP) Huatulco}

La variedad de atractivos y recursos naturales que México ostenta, sumándole la gran diversidad cultural y, en especial, el crecimiento sustancial del turismo de sol y playa, fueron factores detonantes para crear en la década de los 60 el Consejo Nacional de Turismo, el Fondo de Garantía al Turismo (FOGATUR) y el Fondo para el Desarrollo de las Infraestructuras Turísticas (INFRATUR), finalmente se hizo, en 1962, un primer Plan Nacional de Turismo (FONATUR, 2010).

Para mediados de los años 70 y con base en los lineamientos del primer Plan Nacional de Turismo, el gobierno mexicano comenzó una política más participativa en el turismo. Por lo anterior, emprendió el desarrollo de nuevos destinos turísticos integralmente planeados (CIP's): Cancún, Ixtapa, Los Cabos, Loreto y Huatulco. Para respaldar las acciones tomadas se recurrió al financiamiento del Banco de Interamericano de Desarrollo (BID) y el Banco Mundial, teniendo como principal actividad la construcción de infraestructura básica y urbana. Institucionalmente la acciones fueron concentradas en 
el sector financiero y, en particular, las acciones tomadas para la construcción de los nuevos destinos fueron asignadas al Fondo Nacional de Fomento al Turismo (FONATUR), creado en 1974 (FONATUR, 2010).

\section{Localización}

El Municipio de Santa María Huatulco, sitio en donde se asienta el CIP, se encuentra ubicado al sur del Estado de Oaxaca, México; en el litoral del Océano Pacífico, en el distrito de San Pedro Pochutla. El lugar cuenta con 35 kilómetros de costa en los que se ubican 9 bahías: Conejos, Tangolunda, Chahué, Santa Cruz, Maguey, El Órgano, Cacaluta, Chachacual y San Agustín, que en conjunto suman 36 playas (Mendoza et al, 2011).

\section{Población}

El Municipio de Santa María Huatulco está compuesto por seis agencias municipales: Santa Cruz Huatulco, Arroyo Xuchilt, Bajos de Coyula, Bajos del Arenal, San José Cuajinicuil y San José Alemania. Asimismo, lo conforman 40 comunidades. Santa María Huatulco cuenta con una población, de acuerdo con datos recopilados en el año 2010 del Instituto Nacional de Estadística y Geografía (INEGI), de 38,629 de los cuales 18,726 son hombres y 19,903 son mujeres. Por otra parte, este municipio tiene 9,943 hogares de los cuales 2,550 tienen una jefatura femenina y 7,393 con jefatura masculina. En la educación se posee un porcentaje de $3.7(1,459)$ en nivel básico de educación del total de la población, en cuanto a los alumnos egresados del bachillerato el porcentaje es de $0.78 \%$. (INEGI, 2011).

\section{Actividades económicas}

Las principales actividades económicas de Santa María Huatulco son la agricultura y el turismo. En el año 2009 se tuvieron 6,332 hectáreas sembradas en el municipio de un total de 1,383,749 registradas en todo el estado de Oaxaca (INEGI, 2011). La producción agrícola se realiza en forma individual, en pequeñas unidades de producción denominadas parcelas, las cuales comprenden una superficie promedio de diez hectáreas por campesino (Palacios y Martínez, 2007).

Por otro lado, a partir de su designación como Centro Integralmente Planeado, en 1984, en 2001, hubo flujos de inversión importantes hacia Huatulco que se han canalizado, en forma preferente, hacia la porción oriental del polígono expropiado por el gobierno federal a cargo de FONATUR (Vázquez citado en Huerta y Sánchez, 2011; 547) y de esta manera el turismo se convirtió en el eje de la economía municipal y generó una 
infraestructura adecuada para su promoción.

A principios del año 2004 se implementa en el Centro Integralmente Planeado Bahías de Huatulco el Sistema de Administración Ambiental Earthcheck, sistema desarrollado por EC3 Global para sustentar la certificación internacional Green Globe -marca creada en 1994 por el Consejo Mundial de Viajes y Turismo- como metodología de evaluación y certificación de sustentabilidad para la industria de viajes y turismo aplicable a: empresas, comunidades, así como a áreas o zonas turísticas predeterminadas. (FONATUR, 2005). De esta forma, en el año 2005 Huatulco se convierte en la primera Comunidad Turística Sustentable del Continente Americano certificada bajo el Sistema de Administración Ambiental EarthCheck. Seis años más tarde Huatulco recibió el certificado "Oro" por parte de la Organización EarthCheck debido a las acciones sustentables que ha realizado el municipio en la industria turística principalmente (Equipo Verde Huatulco http://www.evh.org.mx/earthcheck.php consultado enero 2014)

En otro ámbito, el municipio de Santa María Huatulco registra 79 mujeres empresarias de acuerdo con un censo que se realizó en un periodo de 2002-2003, sobresaliendo dos cooperativas conformadas exclusivamente por mujeres de la comunidad de Barra de Copalita, llamadas Mujer de Barro y Flor de Barro creadas en 2005 y 2006 respectivamente, dedicadas a dar masajes exfoliantes con arcilla a los turistas. Además se identificaron 57 empresas referentes a servicios dirigidos al turismo entre los que destacan 35 restaurantes, fondas y bares, y 22 tiendas de artesanías y boutiques, todas ellas dirigidas por mujeres de la comunidad (Fernández y Martínez, 2010), aunque esto no quiere decir que el género masculino sea excluido de las labores empresariales.

De acuerdo con el Censo de Población y Vivienda 2010, 16,144 habitantes (41,79\% de la población total del municipio) son considerados como Población Económicamente Activa (PEA) de los cuales 63,67\% (10,279 del total de la PEA del municipio) son hombres y $36,33 \%(5,865)$ corresponden al género femenino (INEGI 2011), lo que denota la amplia participación de las mujeres en la economía del municipio. Del total de la PEA municipal, 15,771 habitantes son considerados PEA ocupada, y 372 PEA desocupada, por lo que se puede considerar que hay una tasa muy baja de desempleo (INEGI, 2011). Parte de la PEA municipal ocupada, se encuentra distribuida por sector de actividad económica, concentrándose $13.52 \%$ en el sector primario, $13.96 \%$ en el secundario y $71.65 \%$ en el sector terciario. (PDM, 2008). 


\section{Metodología de la Investigación}

El objetivo de esta investigación fue identificar la percepción de los familiares varones de las mujeres empresarias en el sector turístico de Bahías de Huatulco sobre su labor empresarial y los cambios en sus roles de género. Por lo que se seleccionó la entrevista a profundidad como técnica de investigación cualitativa, ya que se consideró la más adecuada para conocer, por medio de la interpretación de los resultados, la percepción de los familiares varones de las mujeres empresarias en el sector turístico de Bahías de Huatulco, que en este caso, fueron las parejas, padres, hermanos o hijos, de las mujeres empresarias de Bahías de Huatulco. La entrevista es una técnica cualitativa que consiste en que una persona (entrevistador) solicita información de otra, para obtener datos sobre un tema determinado a investigar. Consiste en, la interacción verbal de por lo menos dos personas (Herrera 2008).

Se entrevistaron a 12 hombres con un rango de edad de 29 a 70 años, los lugares en donde se realizaron las entrevistas fueron, en su mayoría, lugares de trabajo de los informantes. El trabajo de campo se realizó en dos periodos, el primero de ellos fue 12 al 16 de noviembre de 2012 y el segundo, del 26 al 30 de junio de 2013.

Para realizar las entrevistas, fue necesario, primeramente, observar posibles negocios en los que estuvieran hombres. En el primer contacto con los informantes, se les preguntaba si era posible que contestaran algunas preguntas, se les mencionaba el propósito de la entrevista y que el principal requisito para responder ésta era que tuvieran algún familiar femenino que tuviera su propio negocio. Se hizo un muestreo de investigación no probabilístico llamado por conveniencia, ya que no se contaba con el total de la población, es decir, se desconocía la totalidad de mujeres empresarias y, por ende, cuántas de estas eran casadas, tenían hijos o vivían con sus padres. De este modo, el investigador seleccionó que individuos formaron parte de la muestra en relación a la disponibilidad de estos (Canal, 2006). En este tipo de muestreos "la representatividad la determina el investigador de modo subjetivo, siendo este el mayor inconveniente del método ya que no podemos cuantificar la representatividad de la muestra" (Casal y Mateu; 2003; 5). En cuanto al "tamaño de la muestra en este tipo de muestreo no hay criterios ni reglas firmemente establecidas, determinándose en base a las necesidades de información, por ello, uno de los principios que guía el muestreo es la saturación de datos, esto es, hasta el punto en que ya no se obtiene nueva información y ésta comienza 
a ser redundante" (Salamanca y Crespo, 2007; 3). Cada entrevista osciló entre 10 a 20 minutos de duración y se registraron en una audiograbación.

En cuanto a las preguntas que se realizaron siguiendo las características de los indicadores del modelo hegemónico de masculinidad antes mencionado, es decir, se hicieron preguntas cumpliendo con el perfil de proveedor, toma de decisiones y protector, además de las preguntas sociodemográficas.

\section{Miradas Masculinas y las Mujeres Empresarias}

\section{Perfil de los entrevistados}

Las características generales de los doce hombres entrevistados son las siguientes: su edad osciló entre 29 y 70 años, las ocupaciones que desempeñan: son artesanos, pescadores y campesinos, sin embargo estos últimos realizan también demostraciones a turistas de la fabricación de adobe y el tejido de palma. Los entrevistados fueron dos hermano y diez esposos de mujeres empresarias o dueñas de negocios turísticos. En cuanto a su escolaridad cinco de los informantes no tuvieron estudios, cuatro cursaron un nivel básico, dos un nivel medio superior y uno con nivel superior.

A continuación se presentan los resultados de las entrevistas en relación a los roles que caracteriza al modelo hegemónico de masculinidad. Según este modelo los hombres deben cumplir con el rol de proveedor, ser quien se encarga de la integridad de la familia y quien tome las decisiones importantes o trascendentes que afecten al núcleo familiar.

\section{Proveedor}

En esta clasificación, se seleccionaron los testimonios que aluden al rol de proveedor que, en este caso, no es desempeñado únicamente por el varón, ya que la mujer también aporta económicamente al hogar. Es decir, en esta sección se presenta la percepción o lo que piensan los hombres de que las mujeres hayan incursionado en un negocio o empresa.

Este es el caso de Manuel quien tiene una tienda y taller de artesanías al igual que su hermana. Dada la relación de hermandad con la mujer empresaria, el informante no participa directamente en el negocio de su hermana, la ayuda que le proporciona es 
surtir de artesanías el negocio propio y el de su hermana que es madre soltera y, por lo tanto, considera que es conveniente que la mujer tenga sus propios ingresos:

"Yo creo que está bien porque no dependen de nadie y eso es bueno, porque eso les ayuda a ellas, en el caso de la madre soltera, a superarse solas, pueden criar hijos siendo madre soltera y se puede criar hijos siendo padre soltero también, creo que todo se puede si se quiere, estoy de acuerdo en que ellas puedan salir adelante y puedan superarse cada día”.

Por lo tanto, está de acuerdo en que las mujeres trabajen, siempre y cuando no abandonen el rol tradicionalmente asignado: ama de casa:

"Si yo veo correcto que ellas trabajen, siempre y cuando ellas acaten su lugar en la sociedad, puede ser mujer y tener todas las oportunidades, pero no es quitarle su lugar a la mujer pero siempre, mientras ella no pierda el control de lo que es una mujer no va a haber problemas, ella puede trabajar".

Pedro de igual manera mencionó que es bueno que su mujer trabaje ya que es mejor tener dos puntos de vista para aportar ideas en el negocio:

"Aporta muchas ideas también, entonces no nada más enfocarse en una sola cabeza, a veces te limita también mucho, entonces ver varias opciones, en conjunto son mejores, tienes otras visiones que se pueden tomar en cuenta para un mejor desarrollo".

Ramiro en la misma pregunta mencionó que:

"No hay ningún problema, porque cada quien hace lo suyo, lo que platicamos, yo con ella, es de que todos somos unos seres humanos, pensamos, razonamos y nadie es dueño de nadie, eres libre de moverte en tu negocio, tus cosas, no hay problema y equitativamente, yo también tengo mi trabajo y hay veces que requieren de más tiempo".

Por otro lado, Germán menciona que el trabajo que desempeña su esposa no le ha generado problemas ya que las ideas que él tiene se complementan con las de ella, y de la misma forma sucede con su esposa: 
"Hay veces que uno propone una cosa y otro pone otra cosa, pero pues se platica, igual cada quien expone el por qué si o el por qué no, hay cosas que tal vez yo que esté más tiempo pues veo que es lo que más le llama la atención al cliente, pero ella también como mujer pues ve qué es lo que más llamaría más la atención porque ella también tiene más experiencia en esto, porque le ha ayudado a sus papás, ha estado trabajando con ellos y tal vez sabe qué es lo que también se vende más, entonces como que hay una compensación entre la experiencia de ella, por llevar más tiempo, y lo que uno ve, que tal vez sea momentáneo".

Sobre el asunto de que la mujer sea proveedora también, Iván opina que es bueno que las mujeres tengan sus propios ingresos económicos ya que de esta manera apoyan al hombre:

"Pues me parece correcto, porque es un apoyo para uno, sin la mujer no podemos hacer nada, o sea, la mujer es un factor especial para el hombre, para que pueda crecer en todos los aspectos tanto económicos, sociales, como en relaciones".

Cabe mencionar que Pedro y su esposa trabaja juntos en su negocio, ninguno de los dos percibe un sueldo y en cuanto a la manera en que se cubren los gastos señaló que:

"Como estamos muy acostumbrados a estar siempre juntos, vamos a comprar al súper, todo lo que necesite la casa, vamos los dos, normalmente estamos los dos comprando las cosas como del hogar y la despensa, y las cosas que se vayan a comprar en el negocio".

Por su parte, Ramiro argumentó que los gastos de la casa se realizan de acuerdo con los ingresos que cada uno obtenga:

"Bueno, yo sí aporto un poco más que ella, hay veces que ella gana poco y ya como yo tengo un sueldo base, pero en temporada alta ella gana más que yo y ella es la que pone más".

En cuanto al modelo hegemónico de masculinidad en el que la crítica social es fuerte cuando un hombre realiza trabajos domésticos, Germán explicó que las faenas hogareñas, al igual que el trabajo en el negocio, se comparten con la mujer: 
"Igual, vamos a partes compartidas, claro ella como está más tiempo, pues realiza más trabajo, pero cuando estoy en casa los días que me toca descansar, también le ayudo a barrer, trapear, lavar trastes, lo que sea"

Por su parte, Iván indicó que el hecho de que sea hombre no significa que se deba evadir una responsabilidad en el hogar y con los hijos cuando la mujer no está presente:

"Claro, cuando puedo lo hago, no podemos evadir nuestra responsabilidad solo por el hecho de que seas hombre, no puedes cargar a tu hijo, no puedes lavar una taza o hacerle un huevito a tu hija, si la esposa no está, tú debes absorber la responsabilidad".

Cuando un hombre realiza labores que tradicionalmente se asocian con las mujeres, se está haciendo género. Se están modificando dichos roles:

"Las realizamos los dos, le ayudo a cocinar mientras ella trapea, mi hijo acomoda la sala, lavamos juntos, ella enjuagaba, yo tendía la ropa, siempre estamos conviviendo de igual forma, en ese sentido no tengo ningún problema".

Para Fernando las labores domésticas no son un problema y esta nueva perspectiva se enseña a los hijos pues ellos colaboran también en el negocio y, por lo tanto, en las labores del hogar:

"Si, cuando sabemos que vienen los gringos nos ponemos a barrer, hacemos de todo. Mi hijo y mi hija, también vienen a barrer, como todos somos un grupo, somos como cinco, somos un grupo y cuando vienen nos ponemos todos, ayudamos todos para que rápido sea".

\section{Protector}

En este apartado, se reunieron los comentarios que muestran un rol protector, que está caracterizado por ser el varón quien resguarda la integridad de la familia. En este caso, a pesar de ser empresaria y con ello independiente en lo económico, el hombre mantiene el papel de guardián, ya que menciona que es importante saber en dónde se encuentra la mujer en todo momento, argumentando que se vela por su seguridad o integridad: 
"La mayoría del tiempo nos frecuentamos, sí creo que sea importante saber en dónde se encuentra. Siempre trato de cuidar a mi familia, no es necesario que yo vaya a estarlas vigilando, con el sólo hecho de que las vea y sepa que estén bien, porque me preocupan, no por el hecho de que Huatulco sea un lugar calmado no quiere decir que vaya dejar de tomar mis precauciones con respecto a mi familia".

En otro contexto, Germán mencionó que por seguridad, mas no por controlar los movimientos de la mujer, es importante saber en dónde se encuentra su esposa: "Pues hasta determinado punto sin llegar a los celos sí, por seguridad, por ver en dónde está, con quién está, no por checarla obsesivamente sino más bien para estar al tanto por si pasa algo en esa zona, si hay alguna explosión, yo que se, no?, algún accidente, sé que está en algún lugar y oigo que hubo un accidente por ahi, pues uno se preocupa e investiga, si uno no supiera en dónde está y escucha una noticia o algo, pues ni en cuenta y tal vez necesita ayuda en el momento que se pudiera brindar para que la situación no se haga más grave”.

Para Iván no es importante saber en todo momento en qué lugar se encuentra su mujer, ya que ella debe de ser libre y el hombre le debe tener confianza:

"No, porque por eso le damos la confianza, si no tienes la confianza, entonces para qué andas con ella, no tienes por qué estarla cuidando, eso se llama machismo, si tú quieres estar escuchando en dónde está, no, eso no tiene por qué ser, la mujer tiene que ser libre y uno tiene que darle la confianza necesaria, o toda la confianza".

Dentro del mismo punto, Pedro argumentó que es importante saber en dónde se encuentra su esposa, pero no en todo momento:

"No en todo momento, pero sí saber en dónde está, al instante. Sabes que voy a salir, voy con mis amigas regreso en la tarde, pero no a cada rato, también es molesto para uno como hombre como para la mujer, "oye en dónde andas, en el banco, oye ya saliste del banco”, es molesto pues, bueno a mi no me gusta eso".

Para Ramiro no es necesario estar al pendiente a cada momento de su esposa: 
"No, ya somos personas adultas y si hacemos una tontería pues ya también sabemos las consecuencias y luego pues es una locura eso de cuidar a su mujer, todos tenemos una cabeza, somos unas personas, pensamos y si alguna falla pues también somos seres humanos, cortar por lo sano, sin problemas".

\section{Toma de decisiones}

En este apartado se reunieron los testimonios referentes al modelo que impone o prescribe que el hombre de la familia sea quien tome las decisiones. Dicho de otro modo, la costumbre de que el varón es quien determina la última palabra en cualquier cuestión que afecte directamente en la familia.

En cuanto a la toma de decisiones, los entrevistados consideran que hay circunstancias en las que el hombre toma sus propias decisiones, en otro momento se incluye la opinión de la mujer en las disposiciones, sin embargo, nunca se mencionó en las entrevistas que también la mujer puede tomar sus propias decisiones, por lo tanto, no se puede decir que se mantiene una equidad en las decisiones:

"Creo que hay momentos en que el hombre tome sus propias decisiones $y$ hay momentos en que hay que tomar decisiones en conjunto, darle parte a la mujer, darle a saber de lo que tú haces porque prácticamente eres uno con ella y hay que estar en comunicación".

Por ejemplo, Germán es esposo de una mujer que tiene un negocio de artesanías desde hace dos años. Su mujer antes de contar con este negocio, no había realizado ninguna actividad empresarial, cuando se puso en marcha el negocio lo acordaron entre los dos, no fue una decisión que se tomara de manera individual:

"El negocio lo pusimos entre los dos y desde un principio y hasta ahorita, cosas que vamos a comprar o se van a surtir es equitativo".

Por otra parte y tomando como referencia la toma de decisiones, Iván, argumentó que es mejor comentar las decisiones ya que los hombres toman decisiones precipitadamente:

"Las decisiones importantes se comentan, porque si no, nosotros a veces como hombres tomamos unas decisiones muy precipitadas y por eso cometemos errores, si no hay comunicación, y la esposa también debe estar preparada para poder apoyar una decisión que, a ambos, a 
futuro nos repercuta".

Para Pedro es mejor comentar las decisiones ya que de esta manera se tiene una segunda opinión y no se toman de una manera desatinada. En este sentido, es posible que ya exista el germen de la noción de que la mujer es buena tomando decisiones y por ello se debe contemplar su punto de vista:

"No creo, siempre es importante tener una segunda opinión, a veces en lo personal siempre he cometido errores y a veces es malo tomar las decisiones al instante y entonces cuando preguntas, como que ya lo piensas, lo analizas más, tanto ella también, a veces cometemos errores por decisión propia y a veces te dejas llevar por la amistad o la familia, y es cuando empiezan los problemas, siempre mejor ver otro panorama y analizarlo mejor".

En el mismo sentido, Fernando comentó que su esposa es quien toma las decisiones del negocio, ya que él sólo se dedica a vender:

"Pues ella, como ella se da cuenta, para comprar, lo que hace falta, yo nada más me dedico a vender".

En cuanto a las decisiones dentro del hogar, Iván argumentó que esas decisiones las toma su mujer, ya que ella debe decidir qué es lo que le hace falta al hogar:

"No, bueno, ahi las toma ella porque la mujer debe de decidir qué es lo que realmente necesita el hogar, aunque nosotros los que económicamente damos la mayor parte en cuestiones económicas, pero generalmente todo lo que se genera es para la familia, para nuestro hijos porque queremos unos hijos, por lo menos, si nosotros no tuvimos la preparación adecuada, que ellos tengan otra clase de preparación y otros proyectos en su vida".

Por el contrario, Pedro mencionó que las decisiones las toman los dos, ya sea del negocio o del hogar:

"Las decisiones las tomamos los dos, tanto de la casa como del negocio, como ella tiene derecho de mandar en la casa como ella tiene derecho de mandar en el negocio".

Después de analizar los testimonios de los hombres familiares de las mujeres 
empresarias en torno a los roles que se imponen socialmente en el modelo hegemónico de masculinidad, vemos que hay cambios significativos.

\section{CONCLUSIONES}

Tomando en cuenta el modelo hegemónico de masculinidad y los roles que debe cumplir un varón, en relación con la dicotomía que Ortner (citado en Moore, 2004) señala, doméstico/mujer y público/hombre, pudo observarse que se están produciendo cambios en dicho modelo. Una vez que se rompe esta dualidad, es decir, que el hombre no es el único proveedor y la mujer sólo como reproductora, el propio modelo manifiesta su imperfección y las fisuras con las que cuenta, en una sociedad que admite las decisiones de los individuos al elegir su manera de vida.

Por otro lado, el hecho de que las mujeres obtuvieran un trabajo que provee de recursos económicos a la familia ha impulsado a su vez la manifestación de una mayor equidad en las relaciones de género, esto a su vez conlleva un 'apoyo' para los hombres, ya que no sólo se limitan al rol de proveedor sino que realizan labores domésticas que abarcan el cuidado y protección de la familia, toda vez que se requieran y no desempeñen un trabajo remunerado.

Así en aquellas parejas que vimos que comparten el rol de proveedor, ambos trabajan y aportan al ingreso familiar, hay una tendencia a que también se comparta el rol de reproductor, cuidado de los hijos y labores domésticas, aunque también aparecieron los casos en los que la mujer carga con una doble jornada al no contar con la colaboración de los hombres.

Al manifestarse un tendencia hacia la democratización en las relaciones de género en las familias, se impulsan las decisiones de manera compartida, es decir, no sólo el hombre cuenta con la potestad de tomar decisiones por o para la familia. Al aportar económicamente a la familia, las mujeres adquieren la posibilidad para tener voz y voto en las deliberaciones no sólo domésticas.

Durante las entrevistas pudo inferirse que el hombre está cambiando su percepción sobre las mujeres, textualmente se dijo que ahora son menos 'machistas', notan una diferencia entre su forma de pensar de ahora y la que tenían hace 10 años 
cuando no había turismo en el lugar. En este sentido, el hecho de que las mujeres trabajen es un 'apoyo' o un alivio a su responsabilidad como proveedor en un contexto turístico caracterizado por un elevado costo de la vida.

Asimismo, los hombres han aceptado que la mujer junto con ellos, tomen las decisiones debido a que se conciben como más impulsivos y a la mujer la perciben como más reflexiva y analítica, lo que les lleva a tomar mejores decisiones.

En cuanto a la labor empresarial, pudo encontrarse desde el caso en el que cada uno tiene su propio trabajo o negocio de manera independiente, hasta casos en los que ambos colaboran en el negocio repartiéndose las responsabilidades, aunque la mujer lleva la mayor carga, en varios casos se vio que el hombre 'ayuda' en el negocio de la mujer, a veces como su chofer o realizando relaciones públicas.

La iniciativa empresarial de las mujeres no se ve obstaculizada por los padres o maridos, pues permiten que desarrollen sus negocios sin interferir, algunas veces por no tener problemas.

Una mujer empresaria que colabora en el gasto y en el patrimonio familiar constituye un aliento para el hombre en su función de proveedor, no obstante pagan el costo de ver disminuida o compartir su autoridad y su papel de protector, lo que nos lleva a planear una fisura en el modelo hegemónico de masculinidad en el CIP Bahía de Huatulco en buena medida debida a la ampliación de oportunidades de empleos e ingresos para las mujeres. Así puede concluirse que todo cambio en uno de los género remite a un cambio en el otro, por ello no podemos pensar en el empoderamiento de las mujeres empresarias según Fernández y Martínez (2010) en su estudio en Huatulco, sin conocer lo que pasa con sus hombres.

\section{BIBLIOGRAFIA}

Boscán Leal, A, (2008) Las Nuevas Masculinidades. Utopía y Praxis Latinoamericana. (on line) Universidad de Zulia, Maracaibo, Venezuela Vol. 13, número 041. Disponible en en la World Wide Web http://revistas.luz.edu.ve/index.php/upl/ article/viewArticle/7770.

Calatrava Requena, J. (2002) "Mujer y Desarrollo Rural en la Globalización de los 
Proyectos Asistenciales a la Planificación de Género". Globalización y Mundo Rural, Número 803.

Canal Díaz N. (2006) “Técnicas de Muestreo. Sesgos Más Frecuentes” Revista Seden. (on line) Vol. 9. Núm. 4 Disponible en http://www.revistaseden.org/files/9CAP\%209.pdf

Casal, J. y Mateu, E. (2003) “Tipos de Muestreo" CReSA. Centre de Recerca en Sanitat Animal / Dep. Sanitat i Anatomia Animals, Universitat Autònoma de Barcelona, 08193-Bellaterra, Barcelona. Disponible en http://www.slideshare.net/Pandrearodriguez/3-tipos-de-muestreo

Cooper, C., Fletcher J; Fyall, A., Gilber, D. y Wanhill, S. (2007) El turismo. Teoría y Práctica. Síntesis. $3^{\circ}$ ed. España.

De Felipe, I. y Casero, A. (2006). "El papel de la Mujer en el Desarrollo", en Trueba, I. (2006) El fin del hambre en 2025. Madrid: Mundiprensa.

Díaz, C. (2007) “Género y Masculinidades”. Plataforma Equinoccio. El Salvador. Disponible en $\mathrm{http} / /$.. escuelaequinoccio.org.

Fernández, M. J. y Martínez, L. A.. (2010) "Participación de las Mujeres en las Empresas Turísticas Privadas y Comunitarias de Bahías de Huatulco, México. ¿Hacia un Cambio en el Rol de Género?". Cuadernos de Turismo. Número. 26. Disponible en http://revistas.um.es/turismo/article/viewFile/116311/110071

FONATUR- Fondo Nacional de Fomento al Turismo (2005). Centro Turístico Tradicional y Centro Turístico Integralmente Planeado. Oficio de la Dirección Adjunta de Planeación y Asistencia técnica.

FONATUR- Fondo Nacional de Fomento al Turismo (2010). Huatulco: Información General. (online) Disponible en http//:Fonatur.gob.mx/es/proyectos_desarrollos/Huatulco/index.

Frohlick, S. (2012) "Intercambios Fluidos: la Negociación de la Intimidad entre Mujeres Turistas y Hombres Locales en un Pueblo Transnacional del Caribe Costarricense". Anuario de Estudios Centroamericanos, Universidad de Costa Rica. (online) Revistas Académicas Vol. 38. Disponible en http://.revistas.ucr.ac.cr/ index.php/anuario/article/view/1915

Gálvez, L. E. (2007) "Las Fisuras de Modelo de Masculinidad Hegemónica y sus Efectos Sobre la Cohesión Social". Ponencia presentada en Foro Virtual ¿Masculinidades en Cohesión? De la comunidad de Foros Iberoamericanos, (online) COFI. Disponible en http://147.83.75.104/doc/cols_new/contenido/ downloads/obtener?id=2285.

Hegg Ortega, M., Centeno Orozco, R. y Castillo Venerio, M. (2005) Masculinidad y Factores Socioculturales Asociados al Comportamiento de los Hombres Frente a la Paternidad en Centroamérica, Managua: UNFPA- CEPAL.

Herrera, J. (2008) La Investigación Cualitativa. Documento sobre la metodología cualitativa desde sus orígenes. Disponible en http://juanherrera.files.wordpress. 
com/2008/11/investigacion-cuantitativa.pdf

Huerta García, M. A. y Sánchez Crispín, A. (2011) "Evaluación del Potencial Ecoturístico en Áreas Naturales Protegidas del Municipio de Santa María Huatulco, México". Cuadernos de Turismo, Universidad de Murcia, Murcia, España. núm. 27. Disponible en: http://www.redalyc.org/articulo.oa?id=39820898030

INEGI- (2011) Censos y Conteos de Población y Vivienda, Consulta del Censo 2010. Disponible en http://.inegi.org.mx/sistemas/mexicocifras/default.aspx. Consultada el 25 de enero de 2013.

Lamas, M. (1995) "La Perspectiva de Género". Revista de Educación y Cultura de la sección 47 del SNTE. (online) Disponible http://www.latarea.com.mx/articu/ articu8/lamas8.htm.

Lickorish, L., Jenkins, J. y Carson L. (2000) Una Introducción al Turismo. Ed. Síntesis. España.

López Gómez, A. y Güida, C. (2000) Aportes de los Estudios de Género en la Conceptualización Sobre Masculinidad.(online) Facultad de Psicología, Universidad de la República. Disponible en http://iin.oea.org/Cursos_a_distancia/CursosProder2004/Bibliografia_genero/UT1/Lectura.1.5.pdf.

Luna García, M. I. (2009) Evaluación de los Recursos Turísticos Culturales de la Cabecera Municipal de Santa María Huatulco, Oaxaca, para Ser Aprovechados como Atractivos Turísticos. Tesis en Administración Turística. Universidad del Mar, México

Mendoza. M. M.; Monterrubio, J. C.; Fernández, M. J. (2011) “Impactos Sociales del Turismo en el Centro Integralmente Planeado (CIP) Bahías de Huatulco, México". Gestión Turística, (online) núm. 15. Disponible en http://mingaonline.uach.cl/pdf/gestur/n15/art03.pdf.

Moore, H. L. (2004) Antropología y Feminismo. Ediciones Catedra $4^{\circ}$ ed., Instituto de la Mujer. Universidad de Valencia, España

Moya, M. (1999) Percepción social y de personas, en J.F. Morales (Ed.) Psicología Social, $2^{a}$ ed., Madrid, España. McGraw-Hill pp. 47-61.

Nogué i Font, J. (1992) Turismo, Percepción del Paisaje y Planificación del Territorio. Instituto de Estudios Turísticos.(online) D. G. de Política Turística Núm. 115. Disponible en http://dugi-doc.udg.edu/bitstream/handle/10256/4102/turismo_percepcion_paisaje.pdf? sequence $=1$

Nogués, A. M. (2009) “Genealogía de la difícil relación entre antropología social y turismo" Pasos, Revista de Turismo y Patrimonio Cultural Vol. 7, núm. 1, enero, pp. 43-56

Olavarría A, J. (2001) $2^{\circ}$ Encuentro de Estudios de Masculinidades: Identidades, Cuerpos, Violencia y Políticas Públicas. Santiago, Chile: FLACSO-Chile/ Universidad Academia de Humanismo Cristiano/Red de Masculinidades. 182 p. Serie Libros FLACSO

Ortiz, F.; García, M. del P. (2006) Metodología de la Investigación, el Proceso y sus 
Técnicas. México, Ed. Limusa.

Palacios, P. y Martínez, N. (2007) La Agroforestería Comunitaria en Santa María Huatulco Oaxaca, México. (online) Grupo Autónomo para la Investigación Ambiental, A.C. Disponible en http://www.raises.org/documentacion/documentos/manejocampesino/agroforesteria-gaia.pdf

Ramírez, R. L. y García Toro, V. I. (2002) Masculinidad Hegemónica, Sexualidad y Transgresión. The City University of New York Latinoamericanistas. (online) Centro Journal, Vol. XIV, Núm. 1.

Royo, E. (2012) La Ausencia Masculina en el Género, Masculinidad para el Sur Programa: Desarrollo y Cooperación, Fundación CIDOB. Disponible en la World Wide Web http://ongcaps.files.wordpress.com/2012/04/masculinidad-para-elsur.pdf.

Salamanca Castro, A. B. y Crespo Blanco, C. M. (2007) "El Diseño en la Investigación Cualitativa". NURE Investigación Revista Científica de Enfermería Núm. 26.

Santana, A. (1997) Antropología y Turismo. ¿Nuevas hordas, viejas culturas? Ed. Ariel España.

Swain, M. (1989) "Roles de Género en el Turismo Indigenista: Las Molas de los Kuna, Kuna Yala y la Supervivencia Cultural”, en V. L. Smith (1989) Anfitriones e invitados. Antropología del turismo Ed. Edymiond, España.

Tena Guerrero, O. y Jiménez Anaya, P. (2006) “Estrategias para Mantener el Modelo de Masculinidad en Padres Esposos Desempleados". Revistas de Estudio de Género: La Ventana; (online) Número 024. Universidad de Guadalajara, México.

Vargas Melgarejo, L. M. (1994), "Sobre el concepto de Percepción". Alteridades (online) Vol. 4. Núm. 8. Universidad Autónoma Metropolitana Unidad Iztapalapa, México.

Wilson, D. (1991) "Primeros efectos del turismo en Seychelles". En De Kadt, E. (edit) Turismo ¿pasaporte al desarrollo? Endymion, Madrid, pp. 301-345

Recibido: 25/04/2013

Aceptado: 25/05/2013

Arbitrado anónimamente. 
